\title{
Clinical utility of the risperidone formulations in the management of schizophrenia
}

\author{
This article was published in the following Dove Press journal: \\ Neuropsychiatric Disease and Treatment \\ 17 October 2011 \\ Number of times this article has been viewed
}

\section{Vishal Madaan' \\ Durga P Bestha ${ }^{2}$ \\ Venkata Kolli ${ }^{2}$ \\ Saurabh Jauhari ${ }^{2}$ \\ Roger C Burket'}

'University of Virginia Health System, Charlottesville, VA, USA; ${ }^{2}$ Creighton University Medical Center, Omaha, NE, USA
Correspondence: Vishal Madaan University of Virginia Health System, 310 Old Ivy Way, Ste 104, Charlottesville, VA 22903, USA

Tel + I 4342436950

Fax + I 4342436970

Email vm8d@virginia.edu

\begin{abstract}
Risperidone is one of the early second-generation antipsychotics that came into the limelight in the early 1990s. Both the oral and long-acting injectable formulations have been subject to numerous studies to assess their safety, efficacy, and tolerability. Risperidone is currently one of the most widely prescribed antipsychotic medications, used for both acute and long-term maintenance in schizophrenia. Risperidone has better efficacy in the treatment of psychotic symptoms than placebo and possibly many first-generation antipsychotics. Risperidone fares better than placebo and first-generation antipsychotics in the treatment of negative symptoms. Risperidone's long acting injectable preparation has been well tolerated and is often useful in patients with medication nonadherence. Risperidone has a higher risk of hyperprolactinemia comparable to first-generation antipsychotics (FGAs) but fares better than many second-generation antipsychotics with regards to metabolic side effects. In this article, we briefly review the recent literature exploring the role of risperidone formulations in schizophrenia, discuss clinical usage, and highlight the controversies and challenges associated with its use.
\end{abstract}

Keywords: risperidone, schizophrenia, formulation, antipsychotic, side effects

\section{Introduction}

Pharmacotherapy is an essential component of the multimodal treatment approach required to manage complex psychiatric disorders such as schizophrenia and bipolar disorder. Beginning with the serendipitous discovery of chlorpromazine's antipsychotic effects, a number of agents such as perphenazine, fluphenazine, thioridazine, haloperidol, and thiothixene, were developed in the 1950s and 1960s. Haloperidol, which continues to be widely available in various formulations, was first approved by the United States Food and Drug Administration (FDA) in 1967. The abovementioned group of medications is frequently referred to as typical or first-generation antipsychotics (FGAs) which act mainly by blocking the dopaminergic D2 receptors. While the FGAs have demonstrated efficacy in managing the positive symptoms of schizophrenia such as hallucinations, formal thought disorder and delusions, their use is often limited by their adverse effect profile, including the potential for a variety of extrapyramidal side effects (EPSE), such as akathisia, acute dystonia, and tardive dyskinesia (TD). Furthermore, their use does not address negative or cognitive symptoms, and may even be associated with a deleterious impact in such domains. These limitations paved the way for further research to identify and develop novel antipsychotic agents. Clozapine is widely accepted as the first atypical antipsychotic or second-generation antipsychotic (SGA). Though it was initially introduced in the early 1970s, it was withdrawn due to its association with agranulocytosis. It was reintroduced in the late 1980s with stricter 
regulations for monitoring and was thereafter FDA-approved for use for treatment-resistant schizophrenia. Over the last two decades, the SGA group has grown exponentially, with the addition of risperidone, olanzapine, ziprasidone, and quetiapine in the $1990 \mathrm{~s}$, followed by aripiprazole and paliperidone in the next decade. In the last few years, three more SGAs including asenapine, iloperidone, and lurasidone have been added to the treatment armamentarium for pharmacotherapy in patients with schizophrenia. Despite a variety of adverse effects and limitations in efficacy, SGAs are now considered the first line of treatment for schizophrenia.

Another important development linked to the optimal management of schizophrenia has involved the development of various formulations of the SGAs that may be used for different subgroups of patients and for enhancing adherence to the medication regimen, an important component of the treatment of schizophrenia. While depot preparations and liquid formulations are available for enhancing adherence, injectable formulations and dissolving tablets may be used for managing aggressive patients or those who may require acute stabilization of symptoms.

In this review article, we briefly discuss the clinical usage, efficacy, tolerability, and safety, availability of various formulations, and potential adverse effects of one of the earliest available SGAs, risperidone. We briefly appraise the role of risperidone in the treatment of positive symptoms, negative and cognitive symptoms of schizophrenia and as an adjuvant of clozapine. In addition, we discuss literature comparing risperidone's efficacy with FGAs and other atypical antipsychotics. We also describe how risperidone compares to other antipsychotics in terms of traditional antipsychotic side effects and also metabolic side effects, which have emerged to be a significant adverse effect with second-generation antipsychotics.

\section{Risperidone}

Development of risperidone, a benzisoxazole derivative, as an antipsychotic emerged from research studies looking at the lysergic acid diethylamide (LSD) drug model of schizophrenia, since such studies led scientists to target not only dopaminergic (DA) receptor blockade, but also the serotoninergic (5-HT) antagonism. ${ }^{1}$ Risperidone was first approved by the FDA for management of acute schizophrenia in 1993 and for the long-term maintenance treatment of schizophrenia in 2002. Risperidone is now available in a variety of formulations, such as oral tablets, oral solution, orally disintegrating tablets, and as powder for solution for long-acting injection (LAI). The LAI formulation of risperidone (RLAI) and the oral dispersible tablet (ODT) were both approved for use by the FDA in 2003. The ODT formulation is reported to have a rapid onset of action and similar bioequivalence when compared to regular tablets. ${ }^{2}$ It is well tolerated and provides an effective alternative to parenteral haloperidol either alone or in combination with benzodiazepines for the management of severe agitation often associated with acute psychotic conditions. ${ }^{3,4}$ In addition to schizophrenia, risperidone is approved for use either as an adjunctive agent or as monotherapy in the acute phase of manic and mixed episodes of bipolar disorder type I in both adult patients and children aged 10 years and older. It is also approved to treat irritability (to include temper tantrums, deliberate self-injury, and aggressiveness) associated with autism in children and adolescents 5 years and older.

\section{Mechanism of action}

Like all the SGAs, risperidone has significant effects on dopamine (DA) and serotonin (5-HT) receptors (Figure 1). While the pharmacodynamic profile of risperidone is best characterized as a potent D2 antagonist with predominant 5-HT2 antagonistic activity, it is worth noting that the D2 antagonistic action of risperidone is 4-10 times less potent compared to haloperidol. ${ }^{5}$

Risperidone is also an alpha-1-adrenergic receptor blocker, which results in the risk of orthostatic hypotension, sometimes requiring a careful dose titration. It also has affinity for the histaminergic $\mathrm{H} 1$ and alpha-2-adrenergic receptors, with $\mathrm{H} 1$ blockage contributing to sedation, increased appetite, and weight gain. Risperidone is metabolized by cytochrome P450 (CYP) 2D6 and its major metabolite, 9-hydroxyrisperidone, is also an effective antipsychotic.

In this article, we discuss the recent literature focusing on the role of risperidone in the treatment of schizophrenia.

\section{Dosing}

Any dosage regimen should be calibrated to gain maximal beneficial effects and minimize the adverse effects of the medication. Li et al reviewed the literature to find out the

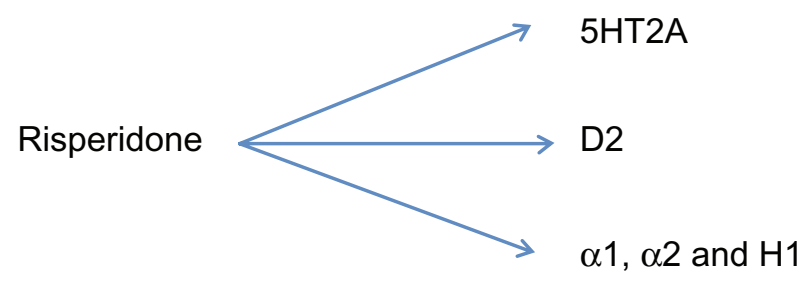

Figure I Mechanism of action of risperidone.

Abbreviations: 5HT2A, serotonin receptor 2A; D2, dopamine receptor 2; HI, histamine receptor $1 ; \alpha 1$, adrenergic receptor I; $\alpha 2$, adrenergic receptor 2 . 
Table I Cochrane risperidone reviews

\begin{tabular}{|c|c|c|c|}
\hline Review & Sample/studies & For risperidone & Against risperidone \\
\hline $\begin{array}{l}\text { Rattehalli et al }{ }^{9} \\
\text { Risperidone vs placebo } \\
\text { for schizophrenia }\end{array}$ & $\mathrm{n}=1363,10 \mathrm{RCT} \mathrm{s}$ & $\begin{array}{l}\text { Greater reduction in PANNS/ } \\
\text { BPRS scores } \\
\text { Less number of risperidone } \\
\text { subjects left the trial owing } \\
\text { to lack of efficacy }\end{array}$ & $\begin{array}{l}\text { More EPSE but did not reach } \\
\text { statistical significance } \\
\text { Prolactin elevation }\end{array}$ \\
\hline $\begin{array}{l}\text { Hunter et al" } \\
\text { Risperidone vs typical } \\
\text { antipsychotic medication } \\
\text { for schizophrenia } \\
\text { Komossa et al }{ }^{14} \\
\text { Risperidone vs other } \\
\text { atypical antipsychotics }\end{array}$ & $\mathrm{n}=7760,45 \mathrm{RCTs}$ & $\begin{array}{l}\text { Better outcomes in both short } \\
\text { and long term trials } \\
\text { Reduction in relapse rate } \\
\text { Less extrapyramidal side effects } \\
\text { Better PANNS score reduction } \\
\text { than quetiapine and ziprasidone } \\
\text { Better than ziprasidone in } \\
\text { leaving study due to inefficacy } \\
\text { Equal efficacy compared to } \\
\text { aripiprazole and amisulpride }\end{array}$ & $\begin{array}{l}\text { Weight gain } \\
\text { Prolactin elevation and sexual } \\
\text { side effects were comparable } \\
\text { to haloperidol } \\
\text { Olanzapine better on PANNS } \\
\text { reduction } \\
\text { Olanzapine and clozapine } \\
\text { better than risperidone in } \\
\text { leaving study due to inefficacy } \\
\text { EPSE } \\
\text { Prolactin elevation }\end{array}$ \\
\hline
\end{tabular}

Abbreviations: RCT, randomized controlled trial; PANNS, positive and negative syndrome scale; BPRS, brief psychiatric scale; EPSE, extra pyramidal side effects.

optimal dose range of risperidone for schizophrenia. ${ }^{6}$ These authors reviewed data from eleven trials involving 2498 (primary outcomes) patients and noted that there is lack of adequate data to recommend the use of a particular dose range for clinical practice. However, first episode psychosis (FEP) patients responded well to doses of $2-4 \mathrm{mg} /$ day. A dose range of 4-6 mg/day seemed optimal for clinical response and tolerability in the majority of schizophrenia patients. Also, patients who received less than $4 \mathrm{mg}$ /day discontinued risperidone due to insufficient response, while patients who received $>10 \mathrm{mg} /$ day stopped taking it due to the higher incidence of side-effects, especially movement disorders.

\section{Risperidone vs placebo}

In general, placebo controlled trials are believed to be easier to interpret than active controlled trials and negate the observed control group bias of atypical antipsychotic active control trials. ${ }^{78}$ In 2010, Rattehalli et al (see Table 1) reviewed ten randomized controlled trials (RCTs) involving 1363 patients, looking at a comparison of risperidone with placebo in treatment of schizophrenia. ${ }^{9}$ Risperidone was found to be better than placebo in reduction of psychotic symptoms as measured by a $>20 \%$ reduction in brief psychiatric rating scale (BPRS) and positive and negative syndrome scale (PANSS) values. Interestingly however, there was no difference between risperidone and placebo in the Clinical Global Impression (CGI) scores. Incidence of EPSE was higher in the risperidone group but did not reach statistical significance when compared to placebo, with a relative risk (RR) of 1.4 and confidence interval (CI) of 0.93-2.1. These authors concluded that while risperidone is better than placebo in marginal improvement of symptoms and in adherence to treatment, they were surprised that even after nearly two decades of availability of risperidone, there is a paucity of independent trials, especially with 7 out of 10 included studies in this review being industry sponsored. In their meta-analysis, Leucht et al reviewed 38 studies comparing SGAs with placebo and concluded that risperidone was more efficacious than placebo and had lower dropout rates. ${ }^{10}$

\section{Risperidone vs other antipsychotics}

There are ethical arguments against placebo controlled trials in schizophrenia and for active controlled trials to be used instead. Risperidone has a favorable side-effect profile and has lower discontinuation rates relative to FGAs. In 2003, Hunter et al (see Table 1) conducted a review of studies comparing risperidone with FGA and noted that risperidone had more favorable outcomes in both short-term and long-term studies and a lower relapse rate at 1-year follow-up when compared to haloperidol. ${ }^{11}$ Risperidone was less likely to be associated with EPSE than haloperidol, with a RR of 0.63 and CI of 0.56-0.71. Therefore, add-on anti-parkinsonian medications were used less often with risperidone. These authors concluded that compared to a similar review in $2000,{ }^{12}$ there was additional evidence to show that risperidone was not only marginally better in terms of clinical improvement but better tolerated in comparison to FGA such as haloperidol as shown by the lower number of risperidone subjects leaving both short- and long-term trials. In a randomized, open-label study involving 174 FEP patients treated with either haloperidol, risperidone, or olanzapine, Crespo-Facorro et al found that the discontinuation rate due to any cause for haloperidol was statistically significant $(P=0.014)$ when compared to the other two medications. ${ }^{13}$ 
Table 2 Major recent studies involving risperidone

\begin{tabular}{|c|c|c|}
\hline Study & Design & Results \\
\hline Geddes et al ${ }^{63}$ & $\begin{array}{l}\text { Systematic review and } \\
\text { meta-regression analysis } \\
52 \text { RCTs }\end{array}$ & $\begin{array}{l}\text { No major difference between typical and atypical antipsychotics } \\
\text { Olanzapine though associated with weight gain, was better } \\
\text { tolerated than risperidone }\end{array}$ \\
\hline Davis et al $^{64}$ & $\begin{array}{l}\text { Meta-analysis } \\
\text { I24 RCTs }\end{array}$ & $\begin{array}{l}\text { Clozapine, olanzapine, risperidone, and amisulpride are more } \\
\text { efficacious than FGAs }\end{array}$ \\
\hline Leucht et al ${ }^{15}$ & $\begin{array}{l}\text { Meta-analysis } \\
\text { I50 double blind studies }\end{array}$ & $\begin{array}{l}\text { Amisulpride, risperidone, clozapine, and olanzapine were more } \\
\text { efficacious than first-generation antipsychotics with small-to- } \\
\text { medium effect sizes } \\
\text { Aripiprazole, quetiapine, sertindole, ziprasidone, and } \\
\text { zotepine were no different in efficacy from first-generation } \\
\text { antipsychotics }\end{array}$ \\
\hline Tiihonen et al ${ }^{65}$ & $\begin{array}{l}\text { Prospective cohort study } \\
\text { using national central registers } \\
\text { in Finland } \\
\mathrm{n}=2230\end{array}$ & $\begin{array}{l}\text { Clozapine, perphenazine depot, and olanzapine had the lowest } \\
\text { rate of discontinuation } \\
\text { Risperidone also had a significantly lower risk of all cause } \\
\text { discontinuation compared with oral haloperidol } \\
\text { Mortality was increased in patients not on antipsychotics }\end{array}$ \\
\hline CATIE ${ }^{18}$ & $\begin{array}{l}\text { Double-blind RCT } \\
\mathrm{n}=1493\end{array}$ & $\begin{array}{l}\text { Phases I and } 2 \\
\text { Phase I: Olanzapine had the longest time to discontinuation; } \\
\text { however had worsening of weight and metabolic profile. } \\
\text { Risperidone was slightly more efficacious than quetiapine and } \\
\text { ziprasidone. Clozapine was superior to risperidone in terms of } \\
\text { improvement in positive symptoms (Phase } 2 E, n=99 \text { ) }\end{array}$ \\
\hline & $\mathrm{n}=444$ & $\begin{array}{l}\text { Phase } 2 \text { T: Risperidone had advantages in those who } \\
\text { discontinued medication owing to intolerability and olanzapine } \\
\text { in those who discontinued owing to inadequate efficacy }\end{array}$ \\
\hline CUtLASS ${ }^{17}$ & $\begin{array}{l}\text { I2-month open-label trial } \\
\mathrm{n}=277\end{array}$ & $\begin{array}{l}\text { Compliance, quality of life, and effectiveness were similar } \\
\text { between FGAs and SGAs }\end{array}$ \\
\hline $\mathrm{SOHO}{ }^{66}$ & $\begin{array}{l}\text { Observational, nonrandomized } \\
\text { study design } \\
n=6516\end{array}$ & $\begin{array}{l}\text { Olanzapine and clozapine were associated with a lower risk of } \\
\text { relapse than risperidone, quetiapine, and typical antipsychotics }\end{array}$ \\
\hline
\end{tabular}

Abbreviations: RCTs, randomized controlled trials; FGAs, first-generation antipsychotics; CATIE, Clinical Antipsychotic Trials of Intervention Effectiveness trial; CUtLASS, Cost Utility of the Latest Antipsychotic drugs in Schizophrenia Study; SGAs, second-generation antipsychotics; SOHO, Schizophrenia Outpatient Health Outcomes study.

Most of the literature supports the notion that there are very few differences in the efficacy of atypical antipsychotics, barring clozapine. More recently, Komossa et al (see Table 1) published an interesting and extensive review of 45 RCTs involving 7760 subjects comparing risperidone with other SGA. ${ }^{14}$ Again, these authors caution that the current data is limited by a preponderance of industry sponsored trials, incomplete reporting of outcomes and a significant proportion (46.9\%) of subject dropouts, thereby preventing them from drawing firm conclusions. Despite these limitations, they inferred that while looking at the PANSS scores, risperidone was slightly better than quetiapine and ziprasidone but marginally inferior to olanzapine. Furthermore, risperidone was inferior to olanzapine and clozapine in terms of subjects discontinuing the study early due to inefficacy although it was superior to ziprasidone in the same measure. There was no significant difference in efficacy between risperidone, amisulpride, and aripiprazole. Risperidone was associated with higher incidence of EPSE and elevated prolactin levels when compared to most of the other
SGAs. In terms of weight gain and metabolic abnormalities, risperidone did worse than amisulpride, aripiprazole, and ziprasidone but better than olanzapine and clozapine.

In their meta-analysis of around 150 studies comparing SGAs with FGAs, Leucht et al (see Table 2) concluded that amongst atypicals, risperidone, clozapine, olanzapine, and amisulpride were superior to first-generation antipsychotics in terms of treating both positive and negative symptoms. However, the other atypicals that were studied including aripiprazole, quetiapine, sertindole, ziprasidone, and zotepine were not more efficacious than FGA even for negative symptoms ${ }^{15}$ Similarly, in another meta-analysis, Leucht et al reviewed 78 randomized and at least single-blinded studies involving 13,558 subjects, which compared several SGAs with each other. ${ }^{16}$ Risperidone was found to be more efficacious than quetiapine and ziprasidone but less efficacious than olanzapine and clozapine (at doses $>400 \mathrm{mg} /$ day). There was no difference in efficacy between risperidone, aripiprazole, and amisulpride. 
The impact of and the limitations associated with the two landmark studies, Clinical Antipsychotic Trials of Intervention Effectiveness (CATIE) trial and the Cost Utility of the Latest Antipsychotic drugs in Schizophrenia Study (CUtLASS; see Table 2), have been extensively debated in the recent literature. Naber and Lambert reviewed these two studies and also looked at the Schizophrenia Outpatient Health Outcomes (SOHO) observational study and the European First-Episode Schizophrenia Trial (EUFEST) and concluded that even though SGAs failed to live up to expectations, several factors in comparison to FGAs such as at least equivalent efficacy, better quality of life-adjusted years (QALYs), and lower risk of tardive dyskinesia (TD) along with the beginning of availability of generic formulations of SGAs make them the favored first-line agents for schizophrenia. ${ }^{17}$ In terms of the CATIE results, probably the most alarming finding of the whole study was the $74 \%$ all-cause discontinuation rate. In Phase I of the CATIE trial involving 1460 subjects, olanzapine was found to be more efficacious, with a lower discontinuation rate than the other medication, but was also the agent most likely to be associated with weight gain and metabolic profile changes. Risperidone had the lowest discontinuation rate due to intolerability but was most associated with elevated prolactin levels. The two components of CATIE Phase II were the 2E (efficacy, clozapine pathway) and 2T (tolerability, ziprasidone pathway), which altogether had 543 patients. Risperidone and olanzapine were more effective than quetiapine and ziprasidone in the 2E. Among Phase I patients who discontinued the assigned agent due to tolerability, many did better on risperidone in the 2T Phase in terms of tolerability and efficacy. Clozapine was clearly effective and better tolerated than all other agents in the $2 \mathrm{E}$ pathway. ${ }^{18}$

\section{Risperidone long acting injectable formulation (RLAl)}

LAI formulations of antipsychotics hold an important position in the treatment of schizophrenia for patients who do not prefer taking medications on a daily basis or for those in whom there is a concern of nonadherence resulting from a number of issues, but especially including lack of insight. Adverse effects, and dosing of LAI formulations of both FGAs and SGAs were discussed in a recent paper by Taylor. ${ }^{19}$ Risperidone was the first SGA to be formulated as a depot form in 2003 , followed later by two other SGAs, paliperidone and olanzapine. RLAI differed from the oil-based preparations of FGA depot formulations by encapsulation of drug molecules into polymeric microspheres. Based on patient needs, RLAI is usually dosed as $25 \mathrm{mg}, 37.5 \mathrm{mg}$, or $50 \mathrm{mg}$ once every
2 weeks and takes about 8 weeks to reach steady plasma levels. Hence, supplementary oral antipsychotic treatment is recommended for the initial 4-6 weeks. RLAI is associated with a lower incidence of EPSE and risk of TD when compared to FGAs. The average weight gain reported with its use was around $3 \mathrm{~kg}$ over a period of 1 year. Other adverse effects include elevated prolactin and transient pain at the injection site. Two of the initial pivotal studies for RLAI involved 1194 patients. In the first study, Kane et al performed a 12-week double-blind, placebo-controlled study in which 554 schizophrenia patients were randomized to receive injections of either placebo or three different doses $(25,50,75 \mathrm{mg})$ of RLAI once every 2 weeks. ${ }^{20}$ All three doses of risperidone were associated with statistically significant reductions in PANSS score $(P<0.05)$ when compared to placebo. RLAI was well tolerated with minimal weight change and the incidence of EPSE was reported to be $13 \%, 10 \%, 24 \%, 29 \%$ in placebo, $25 \mathrm{mg}, 50 \mathrm{mg}$, and $75 \mathrm{mg}$ of RLAI, respectively. There was no added benefit with the higher $75 \mathrm{mg}$ dosage when compared to $50 \mathrm{mg}$; more importantly, the higher dose was associated with a higher adverse effect profile. In another study involving 640 schizophrenia patients, Chue et al used oral risperidone for the first 8 weeks, following which symptomatically stable patients were randomized to RLAI with placebo pills or placebo injections with oral risperidone. ${ }^{21}$ At the end of the study, both groups had a statistically significant reduction in PANSS $(P<0.001)$ and provided evidence for successful transition from oral to injectable form of risperidone in stable patients. A retrospective study involving 174 patients in Sweden found that switching to RLAI resulted in a significant decrease in duration and frequency of inpatient hospital stay. ${ }^{22} \mathrm{~A}$ similar reduction in utilization of inpatient resources was detected in a 6-month follow-up study of 79 patients and the Electronic Schizophrenia Treatment Adherence Registry (e-STAR) study of 1659 patients on RLAI who were followed up for 24 months. ${ }^{23,24}$ In a naturalistic, multicenter European study involving 5134 patients who were followed up for 6 months, $84 \%$ completed the study on RLAI. ${ }^{25}$ Only $2.3 \%$ and $2 \%$ discontinued RLAI due to lack of efficacy and adverse events, respectively. In a 6-month randomized, open-label study of 115 patients with both schizophrenia and substance abuse, patients on a combination of oral and LAI risperidone showed greater reduction in PANSS scores, fewer positive drug screens, and better adherence to substance abuse treatment programs than patients on a combination of oral and LAI zuclopenthixol. ${ }^{26}$ In a 2-year follow-up study of 60 patients with recent onset psychosis who were treated with RLAI, 72\% completed the study while a total of 32 patients achieved remission. ${ }^{27}$ In 2009 , 
Fleischhacker conducted a review of LAI SGA preparations, which included an extensive review of the safety and efficacy of RLAI. ${ }^{28}$ The authors identified a variety of problematic areas with RLAI including high cost, need for initial oral antipsychotic supplementation, lack of guidelines regarding the optimal dosing, and frequency of administration.

\section{Use of risperidone in adolescents}

Schizophrenia is known to be rare in childhood with most reports suggesting that the onset is 50 times less common in children younger than 15 years compared to adults. ${ }^{29}$ Nevertheless, the severe symptoms, which hamper academic and social development frequently in affected adolescents, require medication interventions. Clinically, because of the perceived tolerability (particularly less EPSE) and more benign side effect profiles, the use of SGAs including risperidone rapidly eclipsed the typical agents in children and adolescents. In August 2007, risperidone became the first SGA to be FDA approved for use in adolescent schizophrenia patients and was quickly followed by aripiprazole later that year. Risperidone was approved mainly based on results from two double-blind trials, which demonstrated the safety, tolerability, and efficacy of risperidone in this patient population. ${ }^{30}$ Put together, these two double-blind trials involved 439 patients (ages 13-17 years) with an acute exacerbation of schizophrenia. ${ }^{31,32}$ In the first study, Haas et al compared two dose ranges of risperidone (1-3 and 4-6 mg/day) vs placebo in a 6-week duration study. ${ }^{31}$ The mean reduction in PANSS and CGI scores were significantly higher in both the risperidone groups. It was reported that EPSE, dizziness, and hypertonia were more common in the higher dose group. Compared to the baseline measure, there was $>7 \%$ weight gain in $15 \%$ and $16 \%$ of the lower and higher dose risperidone groups, respectively. The second study compared low dose risperidone $(<1.5 \mathrm{mg})$ to a higher dose range $(1.5-6 \mathrm{mg}){ }^{32}$ Clinical response was greater in the higher dose group (72.6\% vs $49.6 \% ; P<0.001)$. Furthermore, prolactin was more elevated in the high dose group (97\%) compared to the low dose group. Similarly, EPSE incidence was greater in the high dose group (32.8\% vs 9.8\%). Discontinuation rates owing to adverse effects were similar in both groups. Common adverse effects in the high-dose group included somnolence, weight gain, and hypertonia whereas headache, insomnia, agitation, and somnolence were the most common adverse effects in the low-dose group. There is general agreement that particularly in adolescents, as the dosage of risperidone approaches higher ranges, it looks more like a typical antipsychotic agent in terms of EPSE. In addition to the above two trials, since the mid-1990s, there has been at least one other randomized, double blinded trial, five openlabeled studies, and a number of case reports which have looked at the efficacy and safety of risperidone in the child and adolescent population with schizophrenia..$^{30,33-36}$ It has to be noted that patients in this age group are extremely sensitive to adverse effects such as akathisia, acute dystonia, EPSE, and metabolic complications. Hence, clinicians should be extra cautious and initiate treatment with lower starting doses, followed by gradual upward titration based on response, along with stringent monitoring for potential adverse events. Correll et al have suggested detailed strategies for recognizing and monitoring these problematic adverse effects in the pediatric population. ${ }^{37}$ However, even with close monitoring and attention to minimizing adverse effects, medication compliance in the adolescent population can be problematic. One study of adolescents (on various medications) 14 months after hospitalization, found only a $38 \%$ compliance rate even though only $23 \%$ stopped because of side effects. ${ }^{38}$ Findings that increased the risk for noncompliance included general noncompliance with the overall treatment plan and substance abuse. Adolescents with major mood or psychotic disorders including schizophrenia frequently manifest both of these factors.

\section{Risperidone as an adjunct to clozapine in treatment-resistant schizophrenia}

While clozapine is the preferred and most efficacious agent for the management of treatment-resistant schizophrenia, some patients may not respond completely to the use of clozapine only. In such scenarios, it is not uncommon for clinicians to consider augmenting clozapine with another antipsychotic agent. Cipriani et al conducted a literature review on the topic and noted that currently, the few available studies are limited by a small sample size, possible bias, and poor study designs. ${ }^{39}$ Two of the three RCTs included in this review used risperidone as one of the augmenting agents. These authors also published a review which looked at the addition of a second antipsychotic for patients who had a suboptimal response to clozapine. ${ }^{40}$ This review involved 21 studies, of which ten used risperidone. These authors concluded that based on the available evidence, the benefits derived from adding a second antipsychotic to clozapine were modest to negligible.

\section{Risperidone and cognition}

In a review discussing the cognitive and psychomotor effects of risperidone, Houthoofd et al looked at twelve studies 
involving patients with schizophrenia and schizoaffective disorder and reported that patients treated with both oral and LAI formulations of risperidone showed improved cognitive functioning in domains such as processing speed, attention, vigilance, verbal and visual learning, memory, reasoning, and problem solving. ${ }^{41}$ Risperidone did not produce any improvements in social cognition but was surprisingly associated with improved performance in the areas of reasoning, problem solving, and nonverbal working memory. These authors caution that this is based on limited available data and would need to be studied further in well-designed trials. The CATIE trial highlights that cognitive impairment is present in almost all patients and is highly correlated with impairment in functional outcomes. ${ }^{18}$ In contrast to previous reports of the modest benefit of SGAs over FGAs, data from CATIE indicate no differences between SGAs and perphenazine in providing modest cognitive enhancement.

\section{Risperidone and negative symptoms}

Leutcht et al in their meta-analysis of $38 \mathrm{RCT}$ s comparing SGAs with placebo reported modest improvement of negative symptoms with antipsychotics. The effect sizes were smaller for negative symptoms compared to positive symptoms. ${ }^{10}$ The same authors reviewed 150 RCTs comparing FGAs and SGAs, and reported an advantage for amisulpride, clozapine, olanzapine, and risperidone over FGAs. However, aripiprazole, quetiapine, sertindole, ziprasidone, and zotepine did not demonstrate any superiority in efficacy over FGAs in treating negative symptoms. ${ }^{15}$ In a different meta-analysis of 78 studies, Leucht et al could not identify any major differences in SGAs in the treatment of negative symptoms barring a superiority of quetiapine over clozapine shown in two small Chinese studies. ${ }^{16}$ The addition of antidepressant medication to risperidone to improve negative symptoms has also been studied; however, these trials have yielded contradictory results so far. ${ }^{42-45}$

\section{Adverse effects and important considerations}

Risperidone is believed to work more like a FGA at doses of $>6 \mathrm{mg}$ since it blocks more than $80 \%$ of D2 receptors leading to the emergence of akathisia, acute dystonia, and EPSE. ${ }^{46}$ This is one of the key reasons that prompted a gradual upward titration approach in contrast to the initial manufacturer recommended titration of $1 \mathrm{mg}$ twice daily on day 1, $2 \mathrm{mg}$ twice daily on day 2, and $3 \mathrm{mg}$ twice daily on day $3 .{ }^{47}$ As a class, SGAs also carry the risk of TD, although this risk is considered to be significantly less when compared to $\mathrm{FGAs}^{48}{ }^{48}$ In a prospective study comparing risperidone to haloperidol and targeting a patient population older than 66 years, subjects on haloperidol were more likely $(P<0.05)$ to develop TD than the risperidone group. ${ }^{49}$ In the SOHO study, subjects on risperidone were associated with a higher incidence of TD when compared to olanzapine. ${ }^{50}$ The association of SGAs with hyperglycemia, weight gain, dyslipidemia, and overall metabolic syndrome makes it essential that clinicians who prescribe risperidone should be specifically vigilant in monitoring the above mentioned conditions which add to the overall morbidity and mortality among such patients. ${ }^{51,52}$ Simon et al commented on the association of metabolic complications and doses of SGAs and reported that risperidone is associated with moderate risk of weight gain, hyperglycemia, type II diabetes, and low risk for dyslipidemia. ${ }^{53}$ However, due to a relative lack of substantial data, no firm conclusions can be drawn about dose-related metabolic complications of risperidone. In a meta-analysis, Smith et al noted that the relative risk of diabetes with SGAs when compared to FGAs was 1.32 but there is not enough evidence available to differentiate individual antipsychotics based on their risk of precipitating diabetes. ${ }^{54}$ Furthermore, these researchers suggested that due to insufficient data, aripiprazole, ziprasidone, and amisulpride were not included in the analysis. Madhusoodanan et al looked at the risk of hyperprolactinemia with psychotropics and noted that in comparison to other SGAs, risperidone causes more marked elevations in prolactin. ${ }^{55} \mathrm{~A}$ variety of reasons have been cited for this, including the effects of risperidone's metabolite, 9-hydroxy risperidone, and the higher occupancy of D2 at the pituitary level compared to the striatum. The incidence of hyperprolactinemia and its consequences, such as amenorrhea, galactorrhea, gynecomastia, and sexual dysfunction in risperidone-treated patients is $1 \%-10 \%$. When compared to FGAs, the prolactin elevation seen with risperidone was found to be lower in some but higher in other studies. It should be noted that once elevated, the prolactin levels may remain high for many months in some patients. ${ }^{33}$ In an extensive review of tolerability of SGA in schizophrenia and bipolar disorder, Edwards and Smith noted that risperidone was the most widely prescribed SGA in the identified trials and it was also associated with higher risk of nausea, EPSE, anti-cholinergic medication use, and sexual dysfunction when compared to other SGAs. ${ }^{56}$ As a group, SGAs are associated with a $0.2 \%$ risk of incidence of neuroleptic malignant syndrome (NMS). ${ }^{57}$

SGAs are known to cause impaired glucose tolerance and are associated with diabetes. They have an adverse effect 
on lipid profile especially triglycerides. ${ }^{58}$ Risperidone has less hyperglycemic effects relative to olanzapine; however, it also has adverse effects on fasting glucose and plasma glucose following glucose challenge compared to healthy volunteers. ${ }^{59}$ Olfson et al found clozapine, olanzapine, risperidone, quetiapine, and ziprasidone, but not aripiprazole, to be associated with hyperlipidemia. ${ }^{60}$ Rummel-Kluge et al conducted a meta-analysis of 48 studies studying metabolic side effects of atypical antipsychotics, and concluded that olanzapine and clozapine produced more weight gain than other atypical antipsychotics. ${ }^{61}$ Risperidone produced more weight gain than amisulpride, but less than sertindole. Olanzapine and quetiapine caused more increase in cholesterol than risperidone.

\section{Conclusion}

The conceptualization of schizophrenia as a 'tripartite construct' involving dysfunction across the domains of positive symptoms, negative symptoms, and interpersonal deficits, occurred in the $1970 \mathrm{~s} .{ }^{62}$ More than 30 years later, we are still far from finding specific agents that could target these specific symptom clusters optimally. Despite their obvious clinical benefits, both FGAs and SGAs have fallen short of expectations, whereas adverse effects and the requirement of intense monitoring for agranulocytosis limit the use of clozapine. SGAs are increasingly being recognized as a heterogeneous group of medications with their own advantages and disadvantages and an individualized case-by-case pharmacologic approach is being advocated. Similar to other SGAs, the literature available on risperidone is dominated by industry-sponsored research.

Risperidone is well tolerated and has proven efficacy in treating the positive symptoms of schizophrenia, however, it is limited by modest effect sizes for treating negative symptoms. It has a proven role in treating not only patients with acute and chronic schizophrenia, but also those with first episode psychosis or belonging to the adolescent population. Adverse effect profile, especially the risk of hyperprolactinemia and tardive dyskinesia, and metabolic profile must be taken into consideration whilst weighing it against other antipsychotics. While the generic availability of oral risperidone is changing the pharmacoeconomics of schizophrenia treatment to some extent, adverse effects similar to other agents in the SGA group can limit its use. The availability of risperidone in a variety of formulations provides the clinician with a choice of recommending patient-specific SGA preparation. This is especially important in specific subgroup of patients, especially those where adherence to the treatment regimen is questionable. On the other hand, it may not be the most helpful agent in young females due to a significant risk for prolactin elevation. Even so, years of clinical experience, ease of generic availability, and availability in different formulations make risperidone a clinical and research standard for comparing the efficacy of newer or emerging antipsychotic therapies.

\section{Disclosure}

The authors report no conflicts of interest in this work.

\section{References}

1. Colpaert FC. Discovering risperidone: the LSD model of psychopathology. Nat Rev Drug Discov. 2003;2(4):315-320.

2. Van Schaick EA, Lechat P, Remmerie BM, Ko G, Lasseter KC, MannaertE. Pharmacokinetic comparison of fast-disintegrating and conventional tablet formulations of risperidone in healthy volunteers. Clin Ther. 2003;25(6):1687-1699.

3. Normann C, Schmauss M, Bakri N, Gerwe M, Schreiner A. Initial treatment of severe acute psychosis with fast orally disintegrating risperidone tablets. Pharmacopsychiatry. 2006;39(6):209-212.

4. Lim HK, Kim JJ, Pae CU, Lee CU, Lee C, Paik IH. Comparison of risperidone orodispersible tablet and intramuscular haloperidol in the treatment of acute psychotic agitation: a randomized open, prospective study. Neuropsychobiology. 2010;62(2):81-86.

5. Megens AA, Awouters FH, Schotte A, et al. Survey on the pharmacodynamics of the new antipsychotic risperidone. Psychopharmacology (Berl). 1994;114(1):9-23.

6. Li C, Xia J, Wang J. Risperidone dose for schizophrenia. Cochrane Database Syst Rev. October 7, 2009;(4):CD007474.

7. Fleischhacker WW, Czobor P, Hummer M, Kemmler G, Kohnen R, Volavka J. Placebo or active control trials of antipsychotic drugs? Arch Gen Psychiatry. 2003;60(5):458-464.

8. Woods SW, Gueorguieva RV, Baker CB, Makuch RW. Control group bias in randomized atypical antipsychotic medication trials for schizophrenia. Arch Gen Psychiatry. 2005;62(9):961-970.

9. Rattehalli RD, Jayaram MB, Smith M. Risperidone versus placebo for schizophrenia. Cochrane Database Syst Rev. January 20, 2010;(1): CD006918

10. Leucht S, Arbter D, Engel RR, Kissling W, Davis JM. How effective are second-generation antipsychotic drugs? A meta-analysis of placebocontrolled trials. Mol Psychiatry. 2009;14(4):429-447.

11. Hunter RH, Joy CB, Kennedy E, Gilbody SM, Song F. Risperidone versus typical antipsychotic medication for schizophrenia. Cochrane Database Syst Rev. 2003;(2):CD000440.

12. Kennedy E, Song F, Hunter R, Clarke A, Gilbody S. Risperidone versus typical antipsychotic medication for schizophrenia. Cochrane Database Syst Rev. 2000;(2):CD000440.

13. Crespo-Facorro B, Pérez-Iglesias RO, Mata I, et al. Effectiveness of haloperidol, risperidone and olanzapine in the treatment of first-episode non-affective psychosis: results of a randomized, flexible-dose, openlabel 1-year follow-up comparison. J Psychopharmacol. 2011. doi: $10.1177 / 0269881110388332$

14. Komossa K, Rummel-Kluge C, Schwarz S, Schmid F, Hunger H, Kissling W, Leucht S. Risperidone versus other atypical antipsychotics for schizophrenia. Cochrane Database Syst Rev. 2011;(1):CD006626.

15. Leucht S, Corves C, Arbter D, Engel RR, Li C, Davis JM. Secondgeneration versus first-generation antipsychotic drugs for schizophrenia: a meta-analysis. Lancet. 2009;373(9657):31-41.

16. Leucht S, Komossa K, Rummel-Kluge C, et al. A meta-analysis of head-to-head comparisons of second-generation antipsychotics in the treatment of schizophrenia. Am J Psychiatry. 2009;166(2):152-163. 
17. Naber D, Lambert M. The CATIE and CUtLASS studies in schizophrenia: results and implications for clinicians. CNS Drugs. 2009; 23(8):649-659.

18. Manschreck TC, Boshes RA. The CATIE schizophrenia trial: results, impact, controversy. Harv Rev Psychiatry. 2007;15(5):245-258.

19. Taylor D. Psychopharmacology and adverse effects of antipsychotic long-acting injections: a review. Br J Psychiatry Suppl. 2009;52: S13-S19.

20. Kane JM, Eerdekens M, Lindenmayer JP, Keith SJ, Lesem M, Karcher K. Long-acting injectable risperidone: efficacy and safety of the first long-acting atypical antipsychotic. Am J Psychiatry. 2003;160(6): $1125-1132$.

21. Chue P, Eerdekens M, Augustyns I, Lachaux B, Molcan P, Eriksson L, et al. Comparative efficacy and safety of long-acting risperidone and risperidone oral tablets. Eur Neuropsychopharmacol. 2005;15(1): $111-117$.

22. Willis M, Svensson M, Löthgren M, Eriksson B, Berntsson A, Persson U. The impact on schizophrenia-related hospital utilization and costs of switching to long-acting risperidone injections in Sweden. Eur $J$ Health Econ. 2010;11(6):585-594.

23. Apiquian R, Córdoba R, Louzã M. Clinical outcomes of long-acting injectable risperidone in patients with schizophrenia: six-month follow-up from the Electronic Schizophrenia Treatment Adherence Registry in Latin America. Neuropsychiatr Dis Treat. 2010;7:19-26.

24. Peuskens J, Olivares JM, Pecenak J, et al. Treatment retention with risperidone long-acting injection: 24-month results from the Electronic Schizophrenia Treatment Adherence Registry (e-STAR) in six countries. Curr Med Res Opin. 2010;26(3):501-509.

25. Parellada E, Kouniakis F, Siurkute A, Schreiner A, Don L. Safety and efficacy of long-acting injectable risperidone in daily practice: an open-label, noninterventional, prospective study in schizophrenia and related disorders. Int Clin Psychopharmacol. 2010;25(3):149-154.

26. Rubio G, Martinez I, Ponce G, Jimenez-Arriero MA, Lopez-Munoz F, Alamo C. Long-acting injectable risperidone compared with zuclopenthixol in the treatment of schizophrenia with substance abuse comorbidity. Can J Psychiatry. 2006;51(8):531-539.

27. Emsley R, Medori R, Koen L, Oosthuizen PP, Niehaus D, Rabinowitz J. Long-acting injectable risperidone in the treatment of subjects with recent-onset psychosis. J Clin Psychopharm. 2008;28(2):210-213.

28. FleischhackerWW. Second-generation antipsychotic long-acting injections: systematic review. Br J Psychiatry Suppl. 2009;52:S29-S36.

29. Beitchman JH, Childhood schizophrenia: a review and comparison of adult onset schizophrenia. Psychiatric Clin North Am. 1985;8(4): 793-814.

30. Madaan V. Risperidone: a review of efficacy studies in adolescents with schizophrenia. Drugs Today (Barc). 2009;45(1):55-62.

31. Haas M, Unis AS, Armenteros J, Copenhaver MD, Quiroz JA, Kushner SF. A 6-week, randomized, double blind, placebo controlled study of the efficacy and safety of risperidone in adolescents with schizophrenia. $J$ Child Adolesc Psychopharmacol. 2009;19(6):611-621.

32. Pandina G, Kushner S, Singer J, et al. Comparison of two risperidone dose ranges inadolescents with schizophrenia [abstract]. 54th Annu Meet Am Acad Child Adolesc Psychiatry. October 23-28, 2007; Boston, MA.

33. Hellings JA, Zarcone JR, Valdovinos MG, Reese RM, Gaughan E, Schroeder SR. Risperidone-induced prolactin elevation in a prospective study of children, adolescents, and adults with mental retardation and pervasive developmental disorders. J Child Adolesc Psychopharmacol. 2005;15(6):885-892.

34. Toren P, Loar N, Weizman A. Use of atypical neuroleptics in child and adolescent psychiatry. J Clin Psychiatry. 1998;59(12):644-656.

35. Armenteros JL, Whitaker AH, Welikson M, Stedge DJ, Gorman J. Risperidone in adolescents with schizophrenia:an open pilot study. J Am Acad Child Adolesc Psychiatry. 1997;36(5):694-700.

36. Quintana H, Keshavan M. Case study: risperidone in children and adolescents with schizophrenia. J Am Acad Child Adolesc Psychiatry. 1995;34(10):1292-1296.
37. Correll CU, Penzer JB, Parikh UH, et al. Recognizing and monitoring adverse events of second-generation antipsychotics in children and adolescents. Child Adolesc Psychiatric Clin NAm. 2006;15(1):177-206.

38. Lloyd A, Horan W, Borgaro SR, Stokes JM, Pogge DL, Harvey PD. Predictors of medication compliance after hospital discharge in adolescent psychiatric patients. J Child Adolesc Psychopharmacol. 1998;8(2):133-141.

39. Cipriani A, Boso M, Barbui C. Clozapine combined with different antipsychotic drugs for treatment resistant schizophrenia. Cochrane Database Syst Rev. 2009;(3):CD006324.

40. Barbui C, Signoretti A, Mulè S, Boso M, Cipriani A. Does the addition of a second antipsychotic drug improve clozapine treatment? Schizophr Bull. 2009;35(2):458-468.

41. Houthoofd SA, Morrens M, Sabbe BG. Cognitive and psychomotor effects of risperidone in schizophrenia and schizoaffective disorder. Clin Ther. 2008;30(9):1565-1589.

42. Cho SJ, Yook K, Kim B, et al. Mirtazapine augmentation enhances cognitive and reduces negative symptoms in schizophrenia patients treated with risperidone: a randomized controlled trial. Prog Neuropsychopharmacol Biol Psychiatry. 2011;35(1):208-211.

43. Abbasi SH, Behpournia H, Ghoreshi A, et al. The effect of mirtazapine add on therapy to risperidone in the treatment of schizophrenia: a double-blind randomized placebo-controlled trial. Schizophr Res. 2010;116(2-3):101-106.

44. Takahashi H, Sugita T, Higuchi H, Shimizu T. Fluvoxamine augmentation in risperidone-resistant schizophrenia: an open trial. Hum Psychopharmacol. 2002;17(2):95-98.

45. Berk M, Gama CS, Sundram S, et al. Mirtazapine add-on therapy in the treatment of schizophrenia with atypical antipsychotics: a double-blind, randomised, placebo-controlled clinical trial. Hum Psychopharmacol. 2009;24(3)233-238.

46. Stip E. Novel antipsychotics: issues and controversies. Typicality of atypical antipsychotics. J Psychiatry Neurosci. 2000;25(2):137-153.

47. Medscape. Drugs, Diseases and Procedures: Risperidone. Available at: http://reference.medscape.com/drug/risperdal-consta-risperidone342986\#0.

48. Correll CU, Leucht S, Kane JM. Lower risk for tardive dyskinesia associated with second-generation antipsychotics: a systematic review of 1-year studies. Am J Psychiatry. 2004;161(3):414-425.

49. Jeste DV, Lacro JP, Bailey A, Rockwell E, Harris MJ, Caligiuri MP. Lower incidence of tardive dyskinesia with risperidone compared with haloperidol in older patients. J Am Geriatr Soc. 1999;47(6): 716-719.

50. Novick D, Haro JM, Bertsch J, Haddad PM. Incidence of extrapyramidal symptoms and tardive dyskinesia in schizophrenia: thirty-six-month results from the European schizophrenia outpatient health outcomes study. J Clin Psychopharmacol. 2010;30(5):531-540.

51. Wooten J. Metabolic effects of atypical antipsychotics. South Med J. 2007;100(8):771-772.

52. Consensus development conference on antipsychotic drugs and obesity and diabetes. American Diabetes Association; American Psychiatric Association; American Association of Clinical Endocrinologists; North American Association for the Study of Obesity. J Clin Psychiatry. 2004; 65(2):267-272.

53. Simon V, van Winkel R, De Hert M. Are weight gain and metabolic side effects of atypical antipsychotics dose dependent? A literature review. J Clin Psychiatry. 2009;70(7):1041-1050.

54. Smith M, Hopkins D, Peveler RC, Holt RI, Woodward M, Ismail K. First- vs second-generation antipsychotics and risk for diabetes in schizophrenia: systematic review and meta-analysis. $\mathrm{Br} J$ Psychiatry. 2008;192(6):406-411.

55. Madhusoodanan S, Parida S, Jimenez C. Hyperprolactinemia associated with psychotropics - a review. Hum Psychopharmacol. 2010;25(4): 281-297.

56. Edwards SJ, Smith CJ. Tolerability of atypical antipsychotics in the treatment of adults with schizophrenia or bipolar disorder: a mixed treatment comparison of randomized controlled trials. Clin Ther. 2009;31 Pt 1:1345-1359. 
57. Trollor JN, Chen X, Sachdev PS. Neuroleptic malignant syndrome associated with atypical antipsychotic drugs. CNS Drugs. 2009;23(6): 477-492.

58. Taylor D, Paton C, Kapur S. The Maudsley Prescribing guidelines. 10th ed. London, UK: Informa Healthcare; 2009.

59. Newcomer JW, Haupt DW, Fucetola R, et al. Abnormalities in glucose regulation during antipsychotic treatment of schizophrenia. Arch Gen Psychiatry. 2002;59(4):337-345.

60. Olfson M, Marcus SC, Corey-Lisle P, Tuomari AV, Hines P, L'Italien GJ. Hyperlipidemia following treatment with antipsychotic medications. Am J Psychiatry. 2006;163(10):1821-1825.

61. Rummel-Kluge C, Komossa K, Schwarz S, et al. Head-to-head comparisons of metabolic side effects of second generation antipsychotics in the treatment of schizophrenia: a systematic review and meta-analysis. Schizophr Res. 2010;123(2-3):225-233.

62. Carpenter WT, Koenig JI. The evolution of drug development in schizophrenia: past issues and future opportunities. Neuropsychopharmacology. 2008;33(9):2061-2079.
63. Geddes J, Freemantle N, Harrison P, Bebbington P. Atypical antipsychotics in the treatment of schizophrenia: systematic overview and meta-regression analysis. BMJ. 2000;321(7273):1371-1376.

64. Davis JM, Chen N, Glick ID. A meta-analysis of the efficacy of second-generation antipsychotics. Arch Gen Psychiatry. 2003;60(6): 553-564.

65. Tiihonen J, Wahlbeck K, Lönnqvist J, et al. Effectiveness of antipsychotic treatments in a nationwide cohort of patients in community care after first hospitalisation due to schizophrenia and schizoaffective disorder: observational follow-up study. BMJ. 2006;333(7561):224.

66. Haro JM, Novick D, Suarez D, Alonso J, Lépine JP, Ratcliffe M; SOHO Study Group. Remission and relapse in the outpatient care of schizophrenia: three-year results from the Schizophrenia Outpatient Health Outcomes study. J Clin Psychopharmacol. 2006;26(6): 571-578.

\section{Publish your work in this journal}

Neuropsychiatric Disease and Treatment is an international, peerreviewed journal of clinical therapeutics and pharmacology focusing on concise rapid reporting of clinical or pre-clinical studies on a range of neuropsychiatric and neurological disorders. This journal is indexed on PubMed Central, the 'PsycINFO' database and CAS, and is the official journal of The International Neuropsychiatric Association (INA). The manuscript management system is completely online and includes a very quick and fair peer-review system, which is all easy to use. Visit http://www.dovepress.com/testimonials.php to read real quotes from published authors.

Submit your manuscript here: http://www.dovepress.com/neuropsychiatric-disease-and-treatment-journal 